\title{
Desvio de finalidade da Contribuição de Intervenção no Domínio Econômico incidente sobre combustíveis ${ }^{1}$
}

\author{
Carolina Maria Melo de Moura ${ }^{2}$ \\ Diego Souza Gon ${ }^{3}$
}

\begin{abstract}
Resumo
Pretende-se demonstrar o desvio de finalidade da Contribuição de Intervenção no Domínio Econômico incidente sobre combustíveis, defendendo a inconstitucionalidade de sua cobrança quando desrespeitada a afetação da receita. Num primeiro momento, será analisada a regra-matriz de incidência tributária, subsumindo seus critérios à Cide-combustíveis. Após, discorrer-se-á sobre as três finalidades instituídas pela Constituição Federal para a Cide-combustíveis. Por fim, falar-se-á sobre os desvios de finalidade desse tributo, para, então, confirmar a inconstitucionalidade da cobrança de Cide-combustíveis quando não utilizada para os fins constitucionais.
\end{abstract}

Palavras Chave: Cide-combustíveis; Finalidades; Afetação; Inconstitucionalidade.

\section{Introdução}

A contribuição de intervenção no domínio econômico (CIDE) é uma espécie de Contribuição Especial, tributo autônomo criado pela Constituição Federal em seu art. 149, juntamente com as contribuições sociais e as de interesse de categoria profissional ou econômica.

Existem diversas modalidades de CIDE, dentre as quais a incidente sobre a importação e comercialização, no mercado interno, de petróleo e seus derivados, gás natural e seus derivados e álcool etílico combustível, regulada pela Lei 10.336/01 e Lei 10.636/02, objeto desse trabalho. Para facilitar, estará indicada pela sigla Cide-combustíveis.

No primeiro capítulo, será abordada a norma de incidência tributária transportando-a à Cide-combustíveis, momento em que serão demonstrados todos os critérios que compõem a hipótese tributária e a relação jurídica tributária deste tributo, a fim de analisar, brevemente, suas principais características.

\footnotetext{
1 Trabalho apresentado junto à disciplina de Direito Tributário, ministrada pela Prof. Dra. Marlene Kempfer Bassoli, na Universidade Estadual de Londrina.

2 Graduada em Direito pela Universidade Estadual de Londrina.

3 Graduado em Direito pela Universidade Estadual de Londrina.
} 
Posteriormente, serão analisadas as finalidades da arrecadação da Cidecombustíveis, suas três destinações especificadas pela Constituição Federal. Por fim, será demonstrado que, apesar de estabelecida constitucionalmente, a afetação da receita da Cide-combustíveis é desobedecida, sendo destinada a situações diversas daquelas previstas no Texto Magno.

\section{Regra-matriz de incidência tributária}

O ordenamento jurídico tributário é composto por normas de estrutura e normas de comportamento, sendo aquelas os princípios que inspiram a construção normativa e sua interpretação, enquanto as de comportamento são as que contêm a descrição da obrigação jurídica tributária e os deveres instrumentais.

Às normas de comportamento que regulam a obrigação tributária dá-se o nome de regra-matriz de incidência tributária, ou norma jurídica em sentido estrito, pois é ela que delimita o núcleo do tributo.

A norma jurídica tributária é composta por elementos dispersos pelo texto legal, às vezes até em leis diferentes, que se complementam. É trabalho do intérprete do direito buscar esses elementos para construí-la.

Sempre, para que a norma esteja completa, haverá uma hipótese tributária da qual surge uma relação jurídica tributária, sendo aquela composta pelos critérios material, temporal e espacial, enquanto esta pelos critérios pessoal (sujeito ativo e sujeito passivo) e quantitativo (base de cálculo e alíquota).

\subsection{Hipótese tributária}

Hipótese tributária é a descrição de um evento jurídico tributário em lei, sendo uma norma abstrata e geral (n.a.g.), pois relata um fato da vida aplicável a todos indistintamente. Sua projeção no mundo real, ou seja, a realização fática dessa hipótese tributária por alguém se dá pelo fato jurídico tributário, sendo esse uma norma concreta e individual (n.c.i.).

Haverá subsunção do fato jurídico tributário à hipótese tributária quando aquele guardar absoluta identidade ao desenho normativo da hipótese, isto é, quando no mundo 
fático ocorrerem exatamente as descrições contidas em lei (leia-se quando a n.c.i. satisfizer a todos os critérios identificativos da n.a.g.).

Paulo de Barros Carvalho (2005, p. 250) explica:

Para que seja tido como fato jurídico tributário, a ocorrência na vida real, descrita no suposto da norma individual e concreta expedida pelo órgão competente, tem de satisfazer a todos os critérios identificadores tipificados na hipótese da norma geral e abstrata (grifos do autor).

Da subsunção surge automática e concomitantemente ao Estado (sujeito ativo) o poder de exigir a prestação, enquanto a quem praticou o fato (sujeito passivo) o dever de cumprir a obrigação tributária. Esse conseqüente é a relação jurídica tributária, a qual será vista mais à frente.

A hipótese tributária é composta por três critérios identificativos: o critério material, o critério espacial e o critério temporal. O critério material diz respeito a um comportamento humano e é composto por um verbo mais seu complemento. O critério espacial é o local, a área geográfica ou a região específica em que incidirá o tributo. Nem sempre esse critério constará expressamente delimitado em lei, casos esses em que se confunde com a validade territorial da norma. Por fim, o critério temporal indica o exato momento em que o critério material considera-se ocorrido, a partir do qual surge a ralação jurídica tributária.

Analisando a hipótese tributária da Cide-combustíveis temos que seu critério material, descrito pelo art. 3o da Lei 10.336/01, é importar e comercializar no mercado interno gasolina e suas correntes, diesel e suas correntes, querosene de aviação e outros querosenes, óleos combustíveis (fuel-oil), gás liquefeito de petróleo, inclusive o derivado de gás natural e de nafta, e álcool etílico combustível.

O critério espacial, no caso de importação, será a repartição alfandegária em que for processado o desembaraço aduaneiro. Já o da comercialização, por não estar descrito expressamente em lei, se confunde com a validade territorial da lei instituidora desse tributo, razão pela qual será todo o território nacional, pois a CIDE é de competência da União. O critério temporal, por sua vez, é o momento em que o sujeito importou ou em que comercializou no mercado interno os produtos acima referidos. 
Portanto, haverá fato jurídico tributário capaz de gerar a hipótese tributária da Cide-combustíveis quando alguém, por exemplo, comercializar gasolina no mercado interno, em qualquer parte do território nacional. A partir do ato de comercialização da gasolina surgirá à União o direito subjetivo de exigir do contribuinte o dever de pagar Cidecombustíveis, ou seja, estará formada a relação jurídica tributária.

\subsection{Relação jurídica tributária}

É a conseqüência, automática e concomitante, da realização factual da hipótese tributária, implicando às partes, sujeito ativo e sujeito passivo, direitos e obrigações, surgindo um vínculo jurídico entre eles.

Paulo de Barros Carvalho (2005, p. 285), com propriedade, ensina:

Ao preceituar a conduta, fazendo irromper direitos subjetivos e deveres jurídicos correlatos, o conseqüente normativo desenha a previsão de uma relação jurídica, que se instala, automática e infalivelmente, assim que se concretize o fato.

As obrigações são o objeto da relação jurídica tributária e podem ser de cunho patrimonial, chamadas obrigações tributárias, ou de cunho administrativo, os deveres instrumentais. Aquelas, previstas no núcleo da regra-matriz, são sempre de dar, e as outras, espalhadas pela norma tributária, se referem a um fazer ou não-fazer, instituídos para o conhecimento, arrecadação e fiscalização do tributo (CARVALHO, 2005, p. 291). Do não cumprimento da obrigação tributária ou dos deveres instrumentais resultará uma sanção prevista em lei.

Também a relação jurídica tributária é composta por critérios que a identificam: o critério pessoal, que engloba o sujeito ativo e o sujeito passivo, e o critério quantitativo, combinado pela base de cálculo e pela alíquota.

Sujeito ativo é o titular do direito subjetivo de exigir o cumprimento da obrigação tributária. É quem detém capacidade tributária ativa (credor), podendo ser a própria pessoa política que instituiu o tributo, bem como outras pessoas jurídicas de direito público ou privado e até pessoa física, desde que estejam a serviço exclusivo do Estado.

Sujeito passivo, por sua vez, é a pessoa física ou jurídica, privada ou pública, de quem se exige o cumprimento da obrigação tributária e a realização dos deveres 
instrumentais. É quem detém capacidade tributária passiva (devedor). Será, na maioria das vezes, o contribuinte, que é quem realiza o critério material da hipótese; ou então o responsável tributário, terceira pessoa que não tenha realizado o critério material, indicada por lei para assumir obrigações tributárias de seu sucessor.

No critério quantitativo, a base de cálculo se destina a dimensionar a intensidade do critério material para que, combinado à alíquota - quantia aritmética prescrita em lei - seja determinado o valor da obrigação tributária.

Aplicando os critérios da relação jurídica tributária à Cide-combustíveis, temos que o sujeito ativo é a União, enquanto sujeito passivo (contribuinte), conforme art. $2 \stackrel{0}{\text { da Lei }}$ 10.336/01 é o produtor, formulador e importador, pessoa física ou jurídica, dos combustíveis líquidos relacionados no art. 3ำ da mesma lei. Admite-se a figura do responsável tributário, sendo o adquirente de mercadoria de procedência estrangeira, no caso de importação realizada por sua conta e ordem, por intermédio da pessoa jurídica importadora (art. 11).

A base de cálculo, nos termos do art. 40 da Lei 10.366/01, é a unidade de medida adotada para os produtos de que trata o art. 3ํ, quando da sua importação ou comercialização no mercado interno. Assim, a base de cálculo da gasolina, por exemplo, é o metro cúbico $\left(\mathrm{m}^{3}\right)$ e do óleo combustível a tonelada $(\mathrm{t})$.

$\mathrm{O}$ art. 149, §2으, III, CF permite seja a alíquota para a Cide-combustíveis ad valorem ou específica. A Lei 10.336/01, regulado pelo Dec. 5.060/04, adotou a alíquota específica, tendo por base a unidade de medida estipulada no art. 5‥ Atualmente, a alíquota está reduzida a zero para a maioria dos produtos, com exceção do álcool e da gasolina.

\section{Finalidades destinadas à Cide-combustíveis}

A Cide-combustíveis é um tributo interventivo, o que implica na existência de finalidades próprias como requisitos de validade. A Constituição Federal de 1988, em seu art. 177, §4으, II, traça três finalidades para a Cide-combustíveis, de forma que esta só será válida quando sua arrecadação e posterior destinação tiverem por base uma dessas finalidades, permitindo que o contribuinte seja usuário dos benefícios decorrentes da aplicação dos recursos. Elas devem ser rigorosamente observadas, pois, caso contrário, ocorrerá desvio de finalidade e conseqüente inconstitucionalidade de sua arrecadação.

Diz o §4으, II do art. 177: 


\begin{abstract}
A lei que instituir contribuição de intervenção no domínio econômico relativa às atividades de importação ou comercialização de petróleo e seus derivados, gás natural e seus derivados e álcool combustível deverá atender aos seguintes requisitos:

II - os recursos arrecadados serão destinados:

a) ao pagamento de subsídios a preços ou transporte de álcool combustível, gás natural e seus derivados e derivados de petróleo;

b) ao financiamento de projetos ambientais relacionados com a indústria do petróleo e do gás;

c) ao financiamento de programas de infra-estrutura de transportes.
\end{abstract}

Em atenção ao disposto na Carta Magna, o art. 1오 §1으 da Lei 10.336/01 dispõe sobre a destinação da Cide-combustíveis, repetindo a redação dada pelo art. 177, §4으, II, CF. Passa-se a verificar cada uma delas.

A necessidade de intervenção com o fim de subsidiar preços ou transporte de álcool combustível, gás natural e seus derivados e derivados de petróleo reside no fato de que esses combustíveis fósseis são fundamentais ao desenvolvimento do país.

São eles que "viabilizam o deslocamento de bens e de pessoas por todo território nacional, escoando a produção agrícola e industrial para a exportação" (VINHA, 2006, p. 168). Além disso, permitem a "manutenção e desenvolvimento do mercado interno, mediante o atendimento do varejo com os produtos da indústria e também da agricultura" (VINHA, 2006, p. 168). Isso justifica a intervenção do Estado, que regula o preço dos combustíveis, aplicando os benefícios diretamente ao contribuinte.

Também é com esse fundamento que se justifica a terceira finalidade da contribuição em análise, pois estão diretamente relacionados. O investimento em infraestrutura de transportes, de qualquer tipo (terrestre, aéreo, marítimo), melhora a locomoção de produtos e pessoas pelo país.

É imprescindível que o Estado se mantenha ativo na conservação de rodovias, tanto que o art. 6o da Lei 10.636/02 traçou como objetivos da Cide-combustíveis a redução do consumo de combustíveis automotivos; o atendimento mais econômico da demanda de transporte de pessoas e bens; a segurança e o conforto dos usuários; a diminuição do tempo de deslocamento dos usuários do transporte público coletivo; a melhoria da qualidade de vida da população; a redução das deseconomias dos centros urbanos e a menor participação dos fretes e dos custos portuários e de outros terminais na composição final dos preços dos produtos de consumo interno e de exportação. 
A segunda finalidade da Cide-combustíveis justifica-se pela preocupação recente com o meio ambiente, que foi devastado e abusivamente utilizado durante o processo de industrialização e urbanização. $\mathrm{O}$ art. 225 , CF diz que é direito de todos um meio ambiente ecologicamente equilibrado e dever do Estado sua defesa e preservação. Além disso, o art. 170, VI, CF trata como um dos princípios da ordem econômica a defesa do meio ambiente, determinando que os agentes econômicos realizem suas atividades evitando o impacto ambiental.

Por isso mesmo, a cobrança de Cide-combustíveis do produtor, formulador e importador de petróleo e seus derivados deve ser revertida para financiamento de projetos ambientais relacionados com a indústria do petróleo e gás.

\section{Desvio de finalidade da Cide-combustíveis}

Como já anteriormente citado, o legislador constitucional e, posteriormente, o legislador ordinário, estabeleceram como elemento intrínseco da Cide-combustíveis o caráter finalístico de suas receitas, vinculando a arrecadação do tributo a três determinadas aplicações constitucionalmente previstas.

Desta forma, o produto da arrecadação tributária da CIDE deverá ser aplicado a três fins, quais sejam: custeio de subsídios de preços ou transporte de combustíveis; financiamento de projetos ambientais relacionados com a indústria do petróleo e do gás e; financiamento de programas de infra-estrutura de transportes, todos previstos constitucionalmente no artigo $177, \S 2$, inciso II. Resta claro, diante da vinculação de receitas, a preocupação do legislador quanto ao dever legal de aplicação da arrecadação proveniente da Cide-combustíveis.

A doutrina é uníssona quanto à classificação da Cide-combustíveis como um tributo vinculado, finalístico, razão pela qual se conclui ser a vinculação de receitas um pressuposto de validade e constitucionalidade do tributo em espécie.

O desrespeito a tal disposição desnatura a finalidade para qual foi instituído a CIDE, implicando em flagrante desvio de finalidade passível de responsabilização do agente público responsável. Do contrário, abre-se a possibilidade do Estado passar a instituir mecanismos interventivos sem se preocupar com a destinação real desses recursos, já que o contribuinte não poderá opor-se à exação. 
Por ser a CIDE um tributo de competência da União, cuja arrecadação deve ser necessariamente aplicada aos fins constitucionalmente previstos, deve o Poder Executivo Federal fiscalizar sua cobrança, arrecadação e destinação.

Eventual desvirtuamento no repasse da arrecadação da CIDE configurar-se-ia em desvio de receita orçamentária passível de responsabilização do infrator, que, na hipótese aventada, é o Presidente da República.

A afirmação acima realizada encontra guarida no artigo 37 caput da CF que ao positivar constitucionalmente, dentre outros, os princípios da legalidade, moralidade e eficiência, garantiu aos cidadãos o dever de conduta austera e responsável de todo e qualquer administrador público.

Cumpre ressaltar que a partir da edição da Lei 8.429/92, a denominada Lei de Improbidade Administrativa, oportunizou-se um instrumento capaz de perseguir atos atentatórios aos princípios previstos no caput do art. 37 da CF.

Mesmo diante da previsão constitucional de aplicação de receitas decorrentes da Cide-combustíveis, e da possibilidade de sanções no caso de seu descumprimento, observase que não estão sendo corretamente destinadas as verbas oriundas da tributação da contribuição interventiva.

Neste sentido, extrai-se trecho do informativo do Senado Federal em que é transcrita decisão do Tribunal de Contas da União (CREMA, 2006):

O Tribunal de Contas da União, conforme documento em apenso, atestou formalmente que os valores arrecadados com a CIDE tiveram a sua destinação constitucional desviada, portanto, houve violação à Constituição e à Lei Orçamentária, isso é inegável.

Vejamos o que decidiu o Tribunal de Contas da União:

GRUPO I - CLASSE V - PLENÁRIO

TC-013.023/2004-5 (com 2 anexos)

Natureza: Acompanhamento

Órgãos: Ministério dos Transportes, Ministério da Fazenda, Ministério do Planejamento, Orçamento e Gestão, Ministério das Cidades e Ministério do Meio Ambiente.

Interessado: Tribunal de Contas da União

Sumário: Acompanhamento. Aplicação dos recursos da Cide-Combustíveis. Constatação de desvio de finalidade. Custeio de despesas administrativas, incompatíveis com o propósito dessa contribuição. Manutenção de grande volume de recursos em caixa, para utilização no cumprimento das metas de superávit primário. Substituição de fontes ordinárias de dotações antigas do Orçamento dos Transportes por receitas proporcionadas pela Cide-Combustíveis. Falta de concretização dos mandamentos constitucionais que justificaram a instituição da contribuição. Determinações. Recomendações. Ciência. 
Ainda sobre o desvio de finalidade, o jornal Folha de São Paulo, em edição de 23/01/2006 divulgou a informação de que, em 2005, o Ministério dos Transportes usou R\$ 2,2 bilhões de recursos que tiveram origem da CIDE (BEGUOCI, 2006).

Desse montante, $\mathrm{R} \$ 1,78$ bilhão foi destinado à infra-estrutura, o restante serviu para pagar salários, encargos sociais e até mesmo a detetização da unidade do DNIT (departamento nacional de infra-estrutura de transportes) de Pernambuco, com dispensa de licitação, no valor de $\mathrm{R} \$ 750,00$. O Ministério dos Transportes afirma que apenas seguiu o orçamento estipulado pelo Ministério do Planejamento.

Inobstante a vedação constitucional do uso de receitas provenientes da Cide-

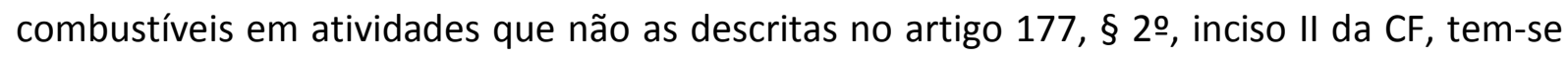
presenciado a aplicação anômala de tais recursos, o que ofende a razão da instituição do tributo em comento.

Agindo desta forma, não há outra conclusão senão a de desvio de finalidade na destinação da arrecadação da Cide-combustíveis e conseqüente comprometimento da razão fundante da medida interventiva.

\section{Conclusão}

O presente artigo científico pretendeu à análise de um dos mais tormentosos temas do Direito Constitucional Tributário, as Contribuições de Intervenção no Domínio Econômico, na sua modalidade Combustíveis.

Para o coerente desenvolvimento do tema realizou-se o estudo da norma jurídica tributária em toda a sua composição, abordando os critérios material, espacial, temporal da norma. Analisou-se também o conseqüente normativo, consubstanciado na relação jurídica tributária e os critérios pessoal e quantitativo aplicados à espécie.

Em seguida, demonstrou-se as finalidades eleitas pelo legislador para aplicação dos recursos advindos da Cide-combustíveis, afirmando o caráter vinculativo do tributo e de suas receitas.

No capítulo subseqüente adentrou-se no problema do desvio de finalidade da arrecadação tributária da $\mathrm{CIDE}$, tributo instituído como fator de intervenção no domínio econômico dos combustíveis e suas correntes, cuja arrecadação está vinculada constitucionalmente a três atividades elencadas no art. 177, § 2ㅇ, II da Lei Maior. 
Inobstante o disposto do texto constitucional acerca da destinação de receitas da CIDE, foi possível a constatação de que efetivamente há desrespeito ao comando constitucional pois, como ficou demonstrado, parte dos recursos obtidos em razão da Cidecombustíveis vem sendo utilizada em a atividades não prevista em lei, tais como despesa com pessoal e encargos sociais e até mesmo manutenção predial da administração pública indireta.

A Cide-combustíveis, tributo de competência da União, exercida em desconformidade com sua finalidade, fere o texto constitucional e a lei instituidora do próprio tributo, fragilizando a posição do contribuinte que, não podendo opor-se à exação, é submetido a uma medida que não se concretiza em seus verdadeiros fins.

\section{Referências}

ATALIBA, Geraldo. Hipótese de Incidência Tributária. 6. ed. São Paulo: Saraiva, 2002.

BEGUOCl, Leandro. Governo não gasta em estrada 83\% de tributo. Folha de São Paulo, São Paulo, 23 jan. 2006. Disponível em:

<http://www1.folha.uol.com.br/fsp/brasil/fc2301200609.htm>. Acesso em: 26 nov. 2006.

CARRAZZA, Roque Antonio. Curso de Direito Constitucional Tributário. 22. ed. São Paulo: Malheiros, 2006.

CARVALHO, Paulo de Barros. Curso de Direito Tributário. 17. ed. São Paulo: Saraiva, 2005.

CREMA, Luís Carlos. Pedido de impeachment contra o Presidente Lula. Jus Navigandi, Teresina, v. 10, n. 946, 04 fev. 2006. Disponível em:

<http://jus2.uol.com.br/pecas/texto.asp?id=670>. Acesso em: 26 nov. 2006.

MACHADO, Hugo de Brito (Coord.). As Contribuições no Sistema Tributário Brasileiro. 1. ed. São Paulo: Dialética/Fortaleza: ICET, 2003.

MELO, José Eduardo Soares de; LIPPO, Luiz Francisco. A Não-Cumulatividade Tributária. 2. ed. São Paulo: Dialética, 2004.

PIMENTA, Paulo Roberto Lyrio. Contribuições de Intervenção no Domínio Econômico. 1. ed. São Paulo: Dialética, 2002. 
VINHA, Thiago Degelo. A Contribuição de Intervenção no Domínio Econômico Incidente Sobre Combustiveis e Derivados. 2006. Disponível em:

<http://www.unimar.br/pos/trabalhos/arquivos/13d9d054109fa6607f8698f2a9494617.pdf> . Acesso em: 03 nov. 2006. 
